\title{
Studying Relationships between Tools of Ethics Management and Organizational Trust of Education Organization in City of Kermanshah Province
}

\author{
Dr. Javad Mehrabi
}

Department of Public Management, Qazvin Branch, Islamic Azad University, Qazvin, Iran

Dr. Mohammad Hossein Mosharaf Javadi

Faculty Member, department of business administration, University of Isfahan, Iran

\section{Kamran AliAbadi}

Department of Public Management, Boroojerd Branch, Islamic Azad University, Boroojerd, Iran

Mohammad Hasan Tanhaei

Department of Management\&Accounting, Qazvin Branch, Islamic Azad University, Qazvin, Iran

\section{Batool Samangoei}

Graduate Student of Business Administration Payame- Nour University, Tehran, Shahre Ray Unit, and Educational Services Expert in University of Isfahan, Iran

Accepted: January 06, 2011 Published: February 03, 2012

Doi:10.5296/ijhrs.v2i1.1356 URL: http://dx.doi.org/10.5296/ijhrs.v2i1.1356

Abstract: Objective of this survey was to study relationships between tools of ethics management and organizational trust

Methods and Research analysis: The present survey has been conducted using descriptive-field-correlation method. Statistical population includes administrative employees of Education Organization in Kermanshah province that are three-hundred persons and 
sample volume has been selected equal to one-hundred seventy persons. Chi-square test $\left(\mathrm{x}^{2}\right)$, assimilation amount of agreement, Fi-Kramer measurement scale and SPSS software have been used in this survey.

Findings: There is a strong significant relationship between tools of ethics management and organizational trust, since the obtained $\mathrm{sig}=0.000<5 \%$ is based on the main research hypothesis and Fi-Kramer is equal to 0.795 .

Conclusion: Using ethics management tools in the organization under study will be leaded to growth and improvement of organizational trust level.

Key words: $\quad$ Organizational Trust, Ethics Management, Ethics Management Tools

\section{Introduction}

Many of the specialists emphasize the importance of human resources as the most important factor of organizations' competitive advantage in the recent age and believe that success of organizations depends on optimized application of these vital factors. Efficient human forces is one of the distinction indexes among the developed and developing countries in the present age that offering high quality and different products and services, reduction of production costs, innovation, creativity and increasing of competitiveness are their characteristics (Hasiri, 2010).

Also managers are looking for strategies to respond to the needs of their human resources. One of these strategies is to establish a close relationship based on trust among employees of the organization. Nihan (2000) defines trust as the trust that one person has in another person in a way that he acts through a predictable, behavioral and fair manner.

Since trust is created by continuous following of ethics codes, it seems that promulgation of ethics codes in the organizations will be resulted in creating and developing of trust. On the other side, trust is a multidimensional concept that includes trust among the individuals, organizational trust, political trust, social trust and etc. Our focus in this survey is on organizational trust that is the existing general trust climate in an organization. In other words, when someone evaluates trust in the framework of inter-organizational expressions in fact it refers to the employees' trust on manager and the manager's trust in employees (Zareimatin, 2010). Thus we can find out role of ethics in creating trust in relationships. Ethics includes concepts such as trustworthiness, rightfulness, fulfillment of the obligation and so on.

\section{Main hypothesis of research}

There is a significant relationship between ethical management and organizational trust.

\section{Secondary hypotheses}

1- There is a significant relationship between ethical codes and organizational trust.

2- There is a significant relationship between ethical training and organizational trust.

3- There is a significant relationship between ethical audit and organizational trust.

4- There is a significant relationship between ethical committee and organizational trust. 
5- There is a significant relationship between attributed phone line for reporting ethics and organizational trust.

\section{Research background}

Organizational trust: Matthai (1989) defines trust as employees' sense of trust in usefulness, ethics stability and statements of the organization while encountering with unstable and risky conditions (Danaeefar, 2010).

According to Mayer organizational trust is more applied to positive expectations of the individuals and those expectations that organizational members have about competency, reliability and benevolence as well as the trust among the organization and individuals (Mulavi, 2011).

Ethics: briefly, ethics consists of recognizing correct from incorrect and then performing what is to be correct and quitting what is to be incorrect (Soltani, 2003).

Ethics means observing spiritual principles and values governing the individual or group's ethics regarding what is correct and what is incorrect (Daft, 1996).

Ethics management: by ethics management in the organization we mean identifying and prioritizing values to direct ethics in the organizations. Organizations can manage ethics in work environment and preserve their ethical performance under disturbed conditions by creating ethics management program (Soltani, 2004).

Ethics management tools: in a paper entitled ethics management in an organization Soltani (2003) has stated tools of ethics management including ethics codes, policies and procedures, techniques to solve ethical difficulties and education.

Ethics audit: it is a systematic and independent activity to study performance of the system to be sure that effective activities on quality are adapted with programmed arrangements (Khademi Zanjani, 2005).

Ethics training: by ethics training we mean to create that extent of recognition in the individual to enable him to perceive the impact of his actions on others well in the organization. In other words, our purpose is to enable the individual to be aware of consequences of his actions on objectives of the organization (Alvani, 2008).

Ethics codes: a group of values that are in priority compared with other values for the organization and should be followed by employees and managers. It includes values like truthfulness, friendship, fulfillment of the obligation, loyalty and etc (Soltani, 2003).

Raminta (2010) has stated tools of ethics management as ethics codes (moral principles), ethics training, ethics audit, ethics committee and attributed phone line for reporting ethics in the organization.

Ethics committee: this committee should be consisted of high rank individuals in the organization and its director is the organization's senior manager. He is directly responsible for solving ethical problems through interpretation of policies and procedures. Duty of this committee is to implement and control ethics management program, training ethical policies and procedures and solving ethical problems (Soltani, 2004).

Attributed phone line for reporting ethics- one of the tools of ethics management in the organization is attributed phone line for reporting ethics or confidential phone line. This method is a strategy to report unethical behaviors in the organization. If this method is 
conducted by a counselor from outside of the organization for example by a legal advisor or a clergyman, it is much better (Alvani, 2008).

\section{Research model}

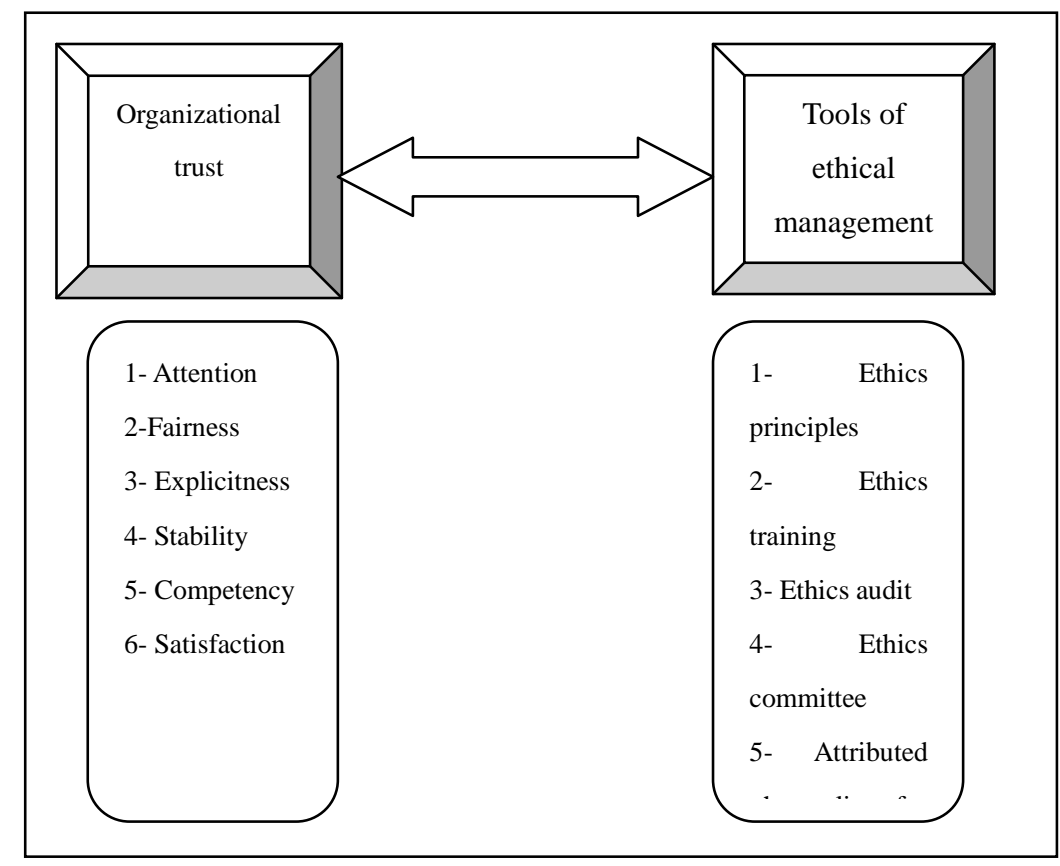

Figure 1-1 conceptual model to study the relationship between tools of ethics management and organizational trust

Raminta (2010)

\section{Research literature}

Raminta et al (2010) conducted a research entitled "creating organizational trust in a social environment with low trust". Purpose of this research was to study the relationship among organizational trust, tools of ethics management and ethical actions of the organization. Research findings refer to the point that tools of ethics management are weakly leaded to create organizational trust in the organizations while organizational actions that observe ethics codes have a more considerable importance in creating organizational trust.

Rowlins (2008) conducted a study entitled "evaluation of the relationship between organizational transparency and employees' trust". He considered three dimensions of competency, integration and goodwill to measure trust and three dimensions of participation, basic information and responsiveness for transparency. Results reveal that:

- There was a positive relationship between organizational transparency and employees' trust. In other words, as employees' perception from organizational transparency is increased, trust of the organization is enhanced according.

- There is a positive relationship among three dimensions of trust and three dimensions of transparency. 
- Degree of trust in those organizations that encourage public participation, distribute basic information, consider themselves responsive by representing fair reports and expose themselves to public quick sight is higher (Hasiri, 2010).

Hasiri, A (2010) performed a research entitled "inter-organizational promotion in the public sector, studying Iran's managerial competency role" on employees of the organizations in Bushehr province. In this research eleven variables were related to inter-organizational trust and twenty eight variables were related to component of managerial competency. Results of the research showed that there is a positive relationship between organizational trust and competency management.

\section{Research methodology}

The present survey was conducted using descriptive-field-correlation method. Statistical population included administrative employees of Education Organization in Kermanshah province that were three-hundred persons. Sample volume was selected equal to one-hundred seventy persons using Morgan table. The sample was selected through random class method. Views of proficient experts were utilized to determine validity of the questionnaire and it was confirmed. Its reliability was calculated equal to 0.911 by means of cronbach alpha coefficient. Chi-square test $\left(\mathrm{x}^{2}\right)$, assimilation amount of agreement, Fi-Kramer measurement scale and SPSS software were used.

\section{Data analysis}

Testing the main hypothesis: There is a significant relationship between tools of ethics management and organizational trust.

\begin{tabular}{rrrrr}
\hline Df & Chistuare test & Asymp.sig & & Volue \\
\hline 4 & 107.471 & 0.000 & cramers Phi & 0.795
\end{tabular}

Table 6- table of square $k$ test and Fi-Kramer assimilation degree related to the main hypothesis Since sig $=0.000<5 \%$ and Fi-Kramer is equal to 0.795 we can conclude that there is a strong significant relationship between tools of ethics management and organizational trust.

Testing secondary hypothesis one: There is a significant relationship between ethical codes and organizational trust.

\begin{tabular}{rrrrr}
\hline Df & ChIstuare test & Asymp.sig & Volue \\
\hline 4 & 35.358 & 0.000 & Cramers Phi & $\mathbf{0 . 4 5 6}$ \\
\hline
\end{tabular}

Table 1- table of square $k$ test and Fi-Kramer assimilation degree related to the first secondary hypothesis

Since sig $=0.000<5 \%$ and Fi-Kramer is equal to 0.456 . We can conclude that there is a strong significant relationship between ethical codes and organizational trust.

Testing secondary hypothesis two: There is a significant relationship between ethics training and organizational trust. 


\section{Df \\ Chistuare test}

Asymp.sig

Volue

4

$4 \quad 32.497$

0.000

cromers Phi

$0 / 456$

Table 2- table of square $k$ test and Fi-Kramer assimilation degree related to the second secondary hypothesis

Since sig $=0.000<5 \%$ and Fi-Kramer is equal to 0.437 we can conclude that there is a strong significant relationship between ethics training and organizational trust.

Testing secondary hypothesis three: There is a significant relationship between ethical audit and organizational trust.

Df Chistuare test Asymp.sig Volue

\begin{tabular}{lllll}
\hline 4 & 39.214 & 0.000 & cromers Phi & $\mathbf{0 . 4 8 0}$
\end{tabular}

Table 3- table of square $k$ test and Fi-Kramer assimilation degree related to the third secondary hypothesis

Since sig $=0.000<5 \%$ and Fi-Kramer is equal to 0.480 we can conclude that there is a strong significant relationship between ethical audit and organizational trust.

Testing secondary hypothesis four: There is a significant relationship between ethics committee and organizational trust.

Df Chistuare test Asymp.sig Volue

\begin{tabular}{lllll}
\hline 4 & 83.132 & 0.000 & cromers Phi & $\mathbf{0 . 6 9 9}$
\end{tabular}

Table 4- table of square $k$ test and Fi-Kramer assimilation degree related to the fourth secondary hypothesis

Since sig $=0.000<5 \%$ and Fi-Kramer is equal to 0.699 we can conclude that there is a strong significant relationship between ethics committee and organizational trust.

Testing secondary hypothesis five: There is a significant relationship between attributed phone line for reporting ethics and organizational trust.

\begin{tabular}{rrrrr}
\hline Df & Chistuare test & Asymp.sig & & Volue \\
\hline 4 & 65.104 & 0.000 & cromers Phi & 0.629
\end{tabular}

Table 5-table of square $k$ test and Fi-Kramer assimilation degree related to the fifth secondary hypothesis

Since sig $=0.000<5 \%$ and Fi-Kramer is equal to 0.619 can conclude that there is a strong significant relationship between attributed phone line for reporting ethics and organizational trust.

\section{Discussion and conclusion}

Raminta et al conducted a study in 2010 entitled "creating organizational trust in societies with low level of trust" in Lithuania. Findings of this study revealed that there existed a weak relationship among tools of ethical management and organizational trust, while findings of the present survey in Iran showed opposite results. 


\section{Al Macrothink

Given that all hypotheses of this survey have been confirmed we can concluded that observing ethical principles, ethical training, conducting ethical audit, establishment of ethical committee and its manner of performance and setting up ethical phone line in the organization and generally using tools of ethical management could be resulted in the growth and enhancement of organizational trust level.

Therefore, we can expect that applying tools of ethical management in Education Organization in Kermanshah province will lead to growth and improvement of organizational trust level. Given to the applicability of this survey it is expected that accurate application of tools of ethical management in organizations in Iran will give rise to growth and improvement of organizational trust level. 


\section{References}

Alvani, Seyed Mehdi (2008), Process of compiling ethics charter for the organization, Journal of Management Culture, No. 15

Daft, Richrd (1996), Theory of the organization and structure planning, translated by Parsaeeian and Erabi, Tehran: business studies and researches publications

Danaeefard, Hassan (2009), Challenges of governmental management in Iran, Tehran: $\quad$ Samt publications

Hasiri, Asad (2010), Studying the role of organizational trust and managerial competence of public managers among governmental organizations in Bushehr province, M.A thesis, Tarbiat Modaress University

Khademi Zanjani, Mehdi (2005), Techniques and trends of audit, Tehran: Asre Keifiat publications

Molavi, Hossein (2011), Studying factorial structure of organizational trust and relationship of its components with organizational learning in universities in the southwest of Iran, Quarterly of Research and Planning in Higher Education, No. 55

Raminta Pucetaite (2010), Anna-Maija Lämsä, Aurelija Novelskaite Source: Baltic Journal of Management Volume: 5 Issue: 22010

Rowlins (2008).Pubic Relation Journal Vol. 2, No. 2, Spring2008 c Public Relation Society of America.

Soltani, Morteza (2004), Ethics management in the organizations, Tadbir, No. 132 Sekaran, Umah (2010), Research methodology in management, translated by

Saebi and Shirazi, Tehran: Higher Institute of Management and Planning

Zareimatin, Hassan (2005), Role of components of organizational culture in building trust, Quarterly of Iran's management sciences, No. 15 